\title{
Comparison of Two Ginkgo biloba L. Extracts on Oxidative Stress and Inflammation Markers in Human Endothelial Cells
}

\author{
Stefano Piazza, ${ }^{1}$ Barbara Pacchetti, ${ }^{2}$ Marco Fumagalli, ${ }^{1}$ Fabrizia Bonacina $\mathbb{D}^{1}{ }^{1}$ \\ Mario Dell'Agli $\mathbb{D}^{1},{ }^{1}$ and Enrico Sangiovanni ${ }^{1}$ \\ ${ }^{1}$ Department of Pharmacological and Biomolecular Sciences, Università degli Studi di Milano, Milano, Italy \\ ${ }^{2}$ Linnea SA, Riazzino, Switzerland \\ Correspondence should be addressed to Mario Dell'Agli; mario.dellagli@unimi.it
}

Received 1 April 2019; Revised 22 May 2019; Accepted 10 June 2019; Published 25 June 2019

Academic Editor: Tânia Silvia Fröde

Copyright (C) 2019 Stefano Piazza et al. This is an open access article distributed under the Creative Commons Attribution License, which permits unrestricted use, distribution, and reproduction in any medium, provided the original work is properly cited.

\begin{abstract}
Atherosclerosis is characterized by interaction between immune and vascular endothelial cells which is mediated by adhesion molecules occurring on the surface of the vascular endothelium leading to massive release of proinflammatory mediators. Ginkgo biloba L. (Ginkgoaceae) standardized extracts showing beneficial effects are commonly prepared by solvent extraction, and acetone is used according to the European Pharmacopoeia recommendations; the well-known Ginkgo biloba acetone extract EGb761 ${ }^{\circledR}$ is the most clinically investigated. However, in some countries, the allowed amount of solvent is limited to ethanol, thus implying that the usage of a standardized Ginkgo biloba ethanol extract may be preferred in all those cases, such as for food supplements. The present paper investigates if ethanol and acetone extracts, with comparable standardization, may be considered comparable in terms of biological activity, focusing on the radical scavenging and anti-inflammatory activities. Both the extracts showed high inhibition of TNF $\alpha$-induced VCAM-1 release (41.1-43.9 $\mu \mathrm{g} / \mathrm{mL}$ ), which was partly due to the NF- $\kappa \mathrm{B}$ pathway impairment. Besides ROS decrease, cAMP increase following treatment with ginkgo extracts was addressed and proposed as further molecular mechanism responsible for the inhibition of endothelial E-selectin. No statistical difference was observed between the extracts. The present study demonstrates for the first time that ethanol and acetone extracts show comparable biological activities in human endothelial cell, thus providing new insights into the usage of ethanol extracts in those countries where restrictions in amount of acetone are present.
\end{abstract}

\section{Introduction}

Atherosclerosis is characterized by a massive chronic inflammation with increased oxidative stress which in turn induces the adhesion of immune cells (i.e., monocytes, leucocytes) to the vascular endothelium and their subsequent migration into the vessel wall. The interaction between immune and vascular endothelial cells is mediated by vascular adhesion molecule-1 (VCAM-1), intercellular adhesion molecule-1 (ICAM-1), and E-selectin occurring on the surface of the vascular endothelium.

In humans, the expression of adhesion molecules has been consistently observed in atherosclerotic plaques [1-3], where high levels of soluble adhesion molecules are considered useful risk predictors of cardiovascular events in healthy populations [4]. Their expression can be transcriptionally regulated by inflammatory cytokines such as tumor necrosis factor- $\alpha$ (TNF- $\alpha$ ), which stimulate adhesion molecules mRNA and cell surface expression through the activation of NF- $\kappa$ B and AP-1 pathways [5]. These transcription factors are redox-sensitive and strongly activated by proinflammatory and prooxidant mediators, including reactive oxygen species (ROS).

The expression of adhesion molecules occurring in several inflammatory models, including TNF- $\alpha$-induced endothelial inflammation, is modulated by the second messenger cyclic AMP (cAMP) as well [6-8]. Notably, molecules able to increase cAMP levels, such as the phosphodiesterase inhibitors (i.e., theophylline), are able to impair leucocyte adhesion in vascular cells [7, 9-11]. Nowadays, botanicals exhibiting anti-inflammatory mechanisms through cAMP increase and NF- $\kappa \mathrm{B}$ inhibition, other than antioxidant 
activity in endothelial cells, are investigated to counteract the development of vascular diseases.

Ginkgo biloba L. is an ancient medicinal plant which has been used in traditional Chinese medicine for thousands of years. Although both leaves and seeds are currently used as herbal medicine in China, leaves are considered the unique source of active principles in many countries, and standardized extracts from leaves are used for supplying pharmaceutical formulations or as ingredient of food supplements.

Phytochemicals occurring in Ginkgo biloba L. leaves include biflavones, terpene trilactones (ginkgolides A, B, C, J, P, and Q and bilobalide), flavonol glycosides, proanthocyanidins, and other polyphenols [12, 13].

Ginkgo biloba leaf extracts show a variety of biological activities, mostly against cardiovascular [14] and neurological diseases, including regulating effects on the entire vascular system of veins, arteries, and capillaries. Ginkgo biloba extracts stimulate lipolysis [15], promote metabolism of brain cells and sensory neurons, and are widely used to treat memory loss, protect against ROS, and improve mild cognitive impairment and cerebrovascular insufficiency [16-19].

Standardized ginkgo extracts should contain flavonoids (22.0-27.0\%), expressed as flavonol glycosides, and 5.0-7.0\% of terpene lactones including ginkgolides $\mathrm{A}, \mathrm{B}$, and $\mathrm{C}$ and bilobalide [20], and the daily dose in adults and elderly should be $240 \mathrm{mg}$ according to EMA monograph [21].

Studies in the literature clearly demonstrate that an adequate standardization of the extracts is mandatory for efficacy, and Ginkgo biloba standardized extracts represent the pharmaceutically used formulations recommended to achieve beneficial effects.

Ginkgo biloba L. standardized extracts are commonly prepared by solvent extraction such as water, methanol, ethanol, or acetone [22]. European Pharmacopoeia recommends extraction of Ginkgo powder with acetone twice for 30 minutes [23]. The clinically investigated extract EGb761 ${ }^{\circledR}$ is an acetone Ginkgo biloba extract [24, 25].

In some countries (i.e., Japan), the amount of acetone allowed in food supplements is limited to ethanol, thus implying that the usage of standardized ethanol extracts is mandatory [26]. However, to the best of our knowledge, no studies have compared the anti-inflammatory and antioxidant effects of acetone and ethanol extracts in human endothelial cells, which are considered one of the preferred biological targets of Ginkgo biloba extracts.

The aim of the present study was (1) to chemically profile aqueous acetone vs. aqueous ethanol extracts from Ginkgo biloba leaves similarly standardized to identify differences among components; (2) to investigate if both the extracts may be considered comparable as anti-inflammatory and antioxidant agents; and (3) to elucidate the mode of action underlying the effect observed in vitro.

\section{Materials and Methods}

2.1. Plant Material and Extraction. G4E (Ginkgo biloba aqueous ethanol extract) and G24 (Ginkgo biloba aqueous acetone extract, EPG246) were prepared by Linnea SA (Riazzino, $\mathrm{CH}$ ) (https://www.linnea.ch/) and provided, as powder, for biological assays. Ginkgo leaves were collected by plantations cultivated in Europe and North America under controlled conditions, according to [27].

For the preparation of Ginkgo biloba G4E, ginkgo leaves were submitted to solid/liquid extraction using aqueous ethanol as extraction solvent. The extracted fractions were then concentrated under reduced pressure to remove the extraction solvent and purified by filtration on resin column and liquid/liquid extractions. For the preparation of G24, Ginkgo biloba leaves were submitted to solid/liquid extraction using aqueous acetone as extraction solvent. The extracted fractions are then concentrated under reduced pressure to remove the extraction solvent and purified by liquid/liquid extractions. In both cases, organic solvent was then replaced with water and the aqueous phase was finally concentrated and dried to obtain the final powdered extract.

Patented standardized extraction and purification processes were applied to obtain extracts with consistent composition in pharmacologically active compounds.

2.2. HPLC Method for Determination of Flavonoids and Terpenes. Flavonoids and terpenes occurring in G24 and G4E were determined according to EP current edition. Briefly, for flavonoid detection, the extracts $(200 \mathrm{mg})$ were dissolved in methanol $(20 \mathrm{~mL}) .15 .0 \mathrm{~mL}$ of diluted hydrochloric acid and $5 \mathrm{~mL}$ of water were added and diluted to $50 \mathrm{~mL}$ with methanol. $10 \mathrm{~mL}$ of the previous solution was hydrolyzed in a $100^{\circ} \mathrm{C}$ water bath for 25 minutes. An aliquot $(10 \mu \mathrm{L})$ of solution was injected: detector: spectrophotometer at $370 \mathrm{~nm}$; column size: $1=0.125 \mathrm{~m}$, diameter $=4 \mathrm{~mm}$; stationary phase: $\mathrm{C} 18(5 \mu \mathrm{m})$; temperature: $25^{\circ} \mathrm{C}$; mobile phase: A: $0.3 \mathrm{~g} / \mathrm{L}$ of phosphoric acid $\mathrm{R}$ adjusted at $\mathrm{pH}=2.0$; mobile phase $\mathrm{B}$ : methanol; gradient elution: time $0(\mathrm{~min})(\mathrm{A}: \mathrm{B}$ $60: 40)$, time 1 (A:B $60: 40)$, time 20 (A:B $45: 55)$, time 21 (A:B $0: 100)$, time 25 (A:B $0: 100)$; flow rate: $1 \mathrm{~mL} / \mathrm{min}$. Quercetin dehydrate was used as reference compound. For terpene determination, the extract $(120 \mathrm{mg})$ was dissolved in phosphate buffer solution $(10 \mathrm{~mL}, \mathrm{pH} 5.8)$ by stirring. Solution was transferred into a column containing $15 \mathrm{~g}$ of kieselguhr. Column was eluted with ethyl acetate $(100 \mathrm{~mL})$. Solvent was evaporated and the residue dissolved in $2.5 \mathrm{~mL}$ of the mobile phase. An aliquot $(100 \mu \mathrm{L})$ of solution was injected: detector: refractometer at $35^{\circ} \mathrm{C}$; column size: $1=$ $0.25 \mathrm{~m}$, diameter $=4 \mathrm{~mm}$; stationary phase: $\mathrm{C} 8(5 \mu \mathrm{m})$; temperature: $25^{\circ} \mathrm{C}$; mobile phase: tetrahydrofuran:methanol: water $(10: 20: 75, v / v)$; flow rate: $1 \mathrm{~mL} / \mathrm{min}$. Method was applied according to the European Pharmacopoeia.

2.3. Cell Culture. Human endothelial cells (HUVECs, CRL1730, ATCC, Virginia, USA), which are immortalized cells with life expectancy of 50-60 doublings according to ATCC specification, were grown at $37^{\circ}$ in Ham's F-12 Kaighn's Medium (Ham F12K) (Sigma-Aldrich, Milano, Italy) supplemented with $100 \mathrm{U}$ penicillin/mL, $100 \mathrm{mg}$ streptomycin $/ \mathrm{mL}$, $2 \mathrm{mM}$ glutamine, and $20 \%$ heat-inactivated foetal calf serum (FCS) (Euroclone S.p.A, Pero, Italy), in a humidified atmosphere containing $5 \% \mathrm{CO}_{2}$. Cells (passage number 2-30) were treated with the indicated concentration of Ginkgo biloba L. 
extracts or vehicle alone (<0.2\% DMSO). Curcumin $10 \mu \mathrm{M}$ was used as reference compound.

2.4. Cytotoxicity. The cytotoxicity of the extracts was evaluated by the 3,4,5-dimethylthiazol-2-yl-5-diphenyltetrazolium bromide (MTT) assay, as previously described [28].

2.5. Measurement of Soluble Adhesion Molecules. For the measurement of soluble ICAM-1, VCAM-1, and E-selectin adhesion molecules, HUVECs were grown in 24-well plates (20,000 cells/well) for $72 \mathrm{~h}$; cells were treated with the proinflammatory stimulus (TNF $\alpha$ at $20 \mathrm{ng} / \mathrm{mL}$ ) and the extracts under study for $6 \mathrm{~h}$. Afterwards, the medium was removed and stored at $-20^{\circ} \mathrm{C}$ until the assays. Soluble ICAM-1, VCAM-1, and E-selectin were quantified in the media by an enzyme-linked immunosorbent assay (ELISA). ICAM-1 was detected by Human ICAM-1 ABTS ELISA development kit (PeproTech, Rocky Hill, NJ, USA) and E-selectin by RayBio Human E-Selectin ELISA (RayBiotech, Norcross, USA), respectively, by measuring in duplicate 200 and $100 \mu \mathrm{L}$ of culture medium and following each manufacturer's instruction. For VCAM-1, Corning 96-well EIA/RIA plates were coated with the rabbit anti-human VCAM-1 (100 pg/well) (PeproTech, USA) overnight at $4^{\circ} \mathrm{C}$. After blocking with BSA, $250 \mu \mathrm{L}$ of samples was transferred into wells at room temperature for $2 \mathrm{~h}$. The amount of VCAM-1 in the samples was detected by using biotinylated rabbit anti-human VCAM-1 antibody (50 pg/well) and streptavidin-HRPconjugated protein (PeproTech, USA). The 3,3',5,5' -tetramethylbenzidine (TMB) substrate reaction was measured by spectrophotometry (signal read: $450 \mathrm{~nm}, 0.1 \mathrm{~s}$ ), and human VCAM-1 standard curve, ranging from 0 to $10 \mathrm{pg} / \mathrm{mL}$, was used to quantify VCAM-1 in the samples. Curcumin $(10 \mu \mathrm{M})$ was used as reference compound.

2.6. Measurement of Cell Surface Adhesion Molecules by Flow Cytometry. HUVECs were plated in 6-well plates $(60,000 /$ well $)$ and treated after 48 hours with TNF $\alpha$ $(20 \mathrm{ng} / \mathrm{mL})$ in the presence of Ginkgo biloba extracts (G4E and G24) for 6 hours. Controls were treated only with the vehicle $(\leq 0.2 \%)$. Cells were then washed once with PBS, harvested, and spun at $2000 \times \mathrm{g}$ for 5 minutes. Cells were stained in $50 \mu \mathrm{L}$ of PBS with $2 \%$ BSA (Sigma-Aldrich) in the presence of the following antibodies: PE-conjugated Mouse anti-Human CD106 (VCAM-1) (BD Pharmingen cod. 555647), APC-conjugated Mouse anti-Human CD54 (ICAM-1) (BD Pharmingen cod. 559771), and PE-Cyconjugated Mouse anti-Human CD62E (E-SEL) (BD Pharmingen cod. 550040). Cells were incubated with antibodies for 30 minutes at $4^{\circ} \mathrm{C}$ in the dark, then washed once in PBS with $2 \%$ BSA (Sigma-Aldrich), spun at $2000 \times$ g, and resuspended in $250 \mu \mathrm{L}$ of PBS/2\% BSA. Cells were acquired with NovoCyte flow cytometer (ACEA Biosciences, San Diego, CA, USA) and analyzed by NovoExpress software (ACEA Biosciences).

2.7. Measurement of Gene Expression by $q R T-P C R$. For mRNA analysis, HUVECs were seeded in $100 \mathrm{~mm}$ plates $\left(5 \times 10^{5}\right.$ cells $\left./ 10 \mathrm{~mL}\right)$ and treated with $\mathrm{TNF} \alpha(20 \mathrm{ng} / \mathrm{mL})$ for 6 hours in the presence of Ginkgo biloba extracts (G4E and G24); mRNA was extracted with RNeasy Mini Kit (Qiagen, Milano, Italy) and quantified by spectrophotometric analysis at $260 \mathrm{~nm}$ (NanoDrop ND-100 spectrophotometer, Euroclone, Italy).

Real-time PCR reactions were performed on $10 \mathrm{ng}$ mRNA/well in the Real-Time System Bio-Rad CFX384 (Bio-Rad, CA, USA) using an $\mathrm{iTaq}^{\mathrm{TM}}$ Universal SYBR Green One-Step Kit (Bio-Rad), which allowed mRNA reverse transcription and cDNA labelling. Amplification of the gene coding for VCAM-1, ICAM-1, or E-selectin (E-SEL) (Primmbiotech, Cambridge, UK) was assessed. The thermal cycling protocol required a preliminary step for reverse transcription at $50^{\circ} \mathrm{C}$ for $10 \mathrm{~min}$, followed by polymerase activation step $\left(95^{\circ} \mathrm{C}, 5 \mathrm{~min}\right)$ and 40 cycles with $95^{\circ} \mathrm{C}$ denaturation step for $10 \mathrm{~s}$ and annealing/extension at $60^{\circ} \mathrm{C}$ for $30 \mathrm{~s}$. All the samples were tested in triplicate, and the relative expression of genes was calculated by normalizing the threshold cycle $(\mathrm{Ct})$ of each gene with the $\mathrm{Ct}$ of GAPDH mRNA to correct for variation in RNA loading. The effect of the extracts on 84 inflammatory cytokines and receptor genes was evaluated by $\mathrm{RT}^{2}$ Profiler PCR Array PAHS$011 Z$ (Qiagen, Milano, Italy).

2.8. Measurement of ROS Production. To evaluate the effect of the extracts on ROS formation, HUVECs were grown in black 96-well plates (10,000 cells/well) for 72 hours and then treated with the extracts for 24 hours. After the treatment, cells were incubated for $1 \mathrm{~h}$ with a fluorescent probe (CMH2DCFDA, Invitrogen by Thermo Fisher Scientific, USA) and then washed with PBS $1 \mathrm{X}$ before the prooxidant stimulation with $\mathrm{H}_{2} \mathrm{O}_{2}(500 \mu \mathrm{M}$ for $1 \mathrm{~h})$. The fluorescence of the internalized probe was read, after a final wash with PBS, by a microplate reader at $535 \mathrm{~nm}$ (Wallac Envision, Perkin Elmer, Waltham MA, USA). Trolox $(500 \mu \mathrm{M})$ or curcumin $(10 \mu \mathrm{M})$ was used as reference compounds.

2.9. NF- $\kappa B$ Nuclear Translocation. To assess the effect of the extracts on the NF- $\kappa \mathrm{B}$ (p65) nuclear translocation, HUVECs were plated in $100 \mathrm{~mm}$ plates at the density of $5 \times 10^{5}$ cells. After $72 \mathrm{~h}$, cells were treated for $1 \mathrm{~h}$ with the proinflammatory mediator and the extracts under study. Nuclear extracts were prepared using Nuclear Extraction Kit from Cayman Chemical Company (Michigan, USA) and stored at $-80^{\circ} \mathrm{C}$ until assayed. The same amount of total nuclear proteins (10 $\mu \mathrm{g} /$ well), quantified by the Bradford method (Bio-Rad), was loaded into the wells. NF- $\kappa \mathrm{B}$ translocation was measured by spectroscopy at $450 \mathrm{~nm}, 0.1 \mathrm{~s}$ (VictorX3, Perkin Elmer, Waltham MA, USA). Data were expressed considering as $100 \%$ the absorbance related to the cytokine-induced NF$\kappa \mathrm{B}$ translocation. The results were the means of at least three experiments performed in duplicate. EGCG $20 \mu \mathrm{M}$ was used as reference compound.

2.10. I $\kappa \mathrm{B} \alpha$ Phosphorylation. The effect of G4E and G24 on $\mathrm{I} \kappa \mathrm{B} \alpha$ phosphorylation was evaluated by IstantOne ${ }^{\mathrm{TM}}$ ELISA (Life Technologies, Carlsbad, USA), using antibodies against both phosphorylated and unphosphorylated forms of $\mathrm{I} \kappa \mathrm{B} \alpha$. Cells were seeded in 12-well plates $(60,000$ cells/well) and incubated with the proteasome inhibitor MG132 $5 \mu \mathrm{M}$ 


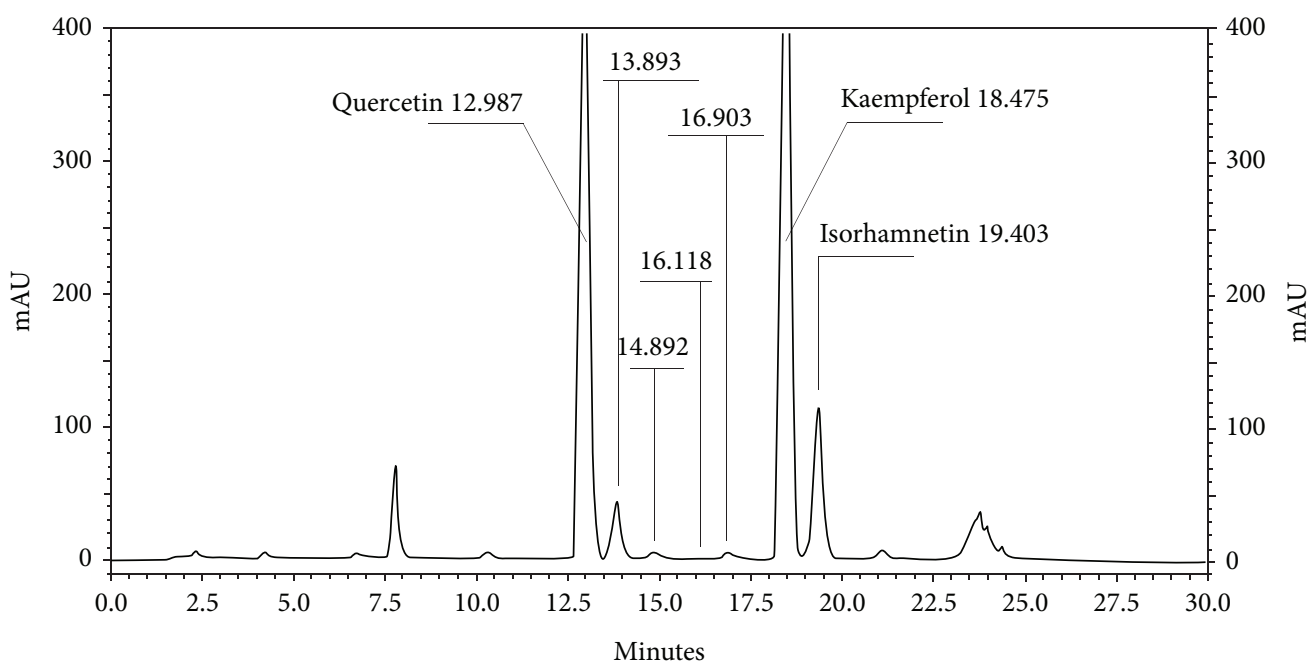

(a)

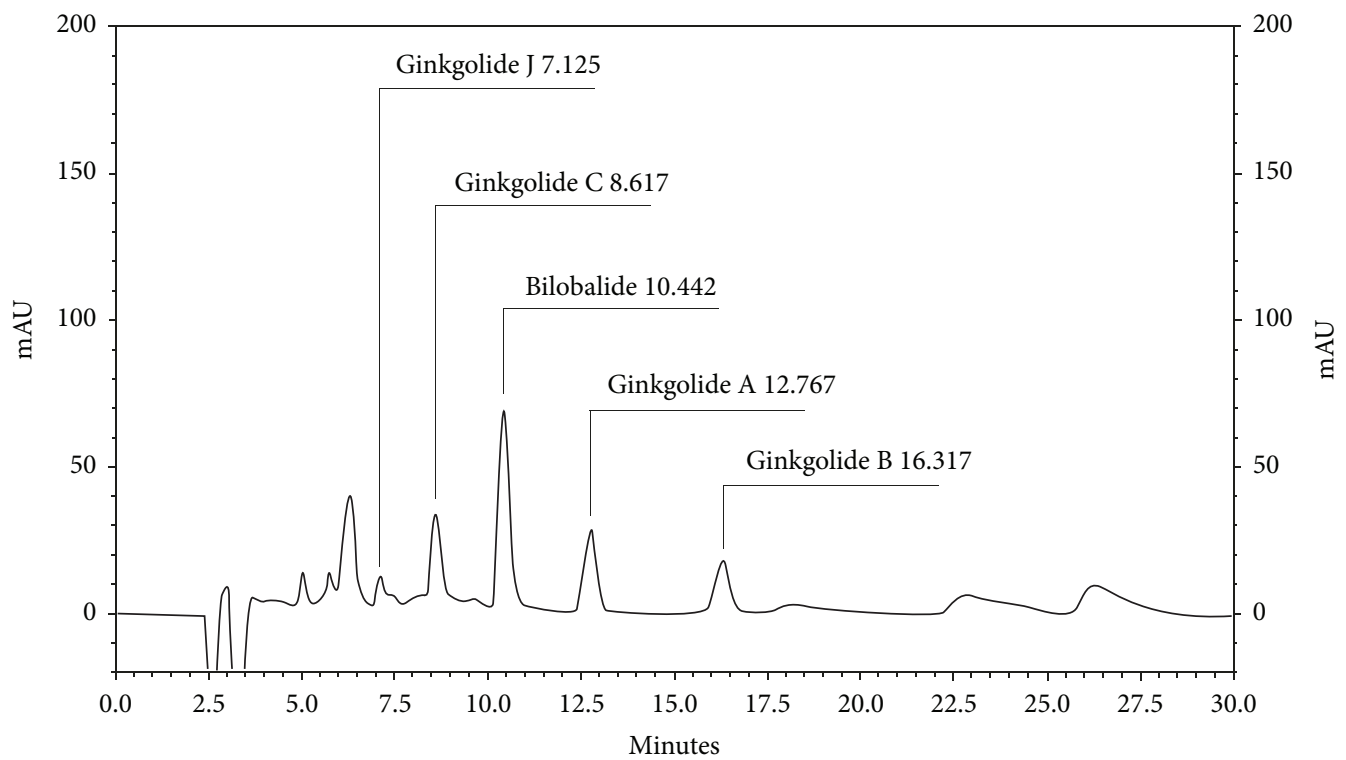

(b)

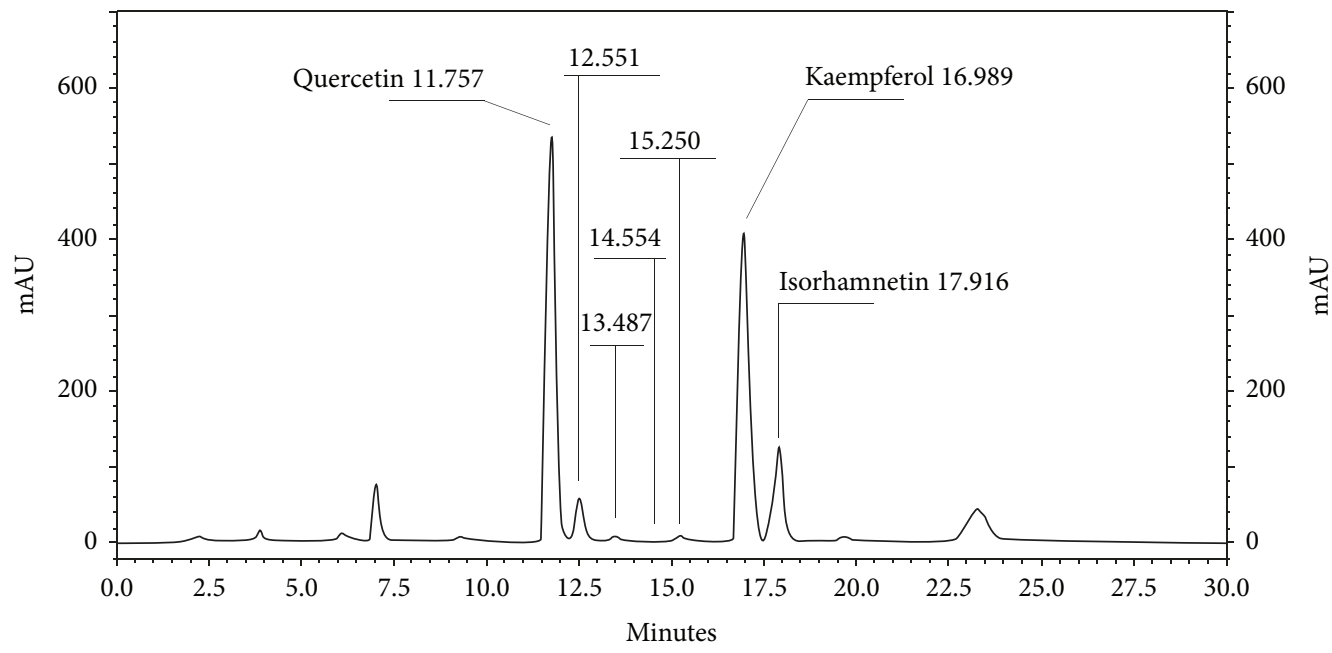

(c)

Figure 1: Continued. 


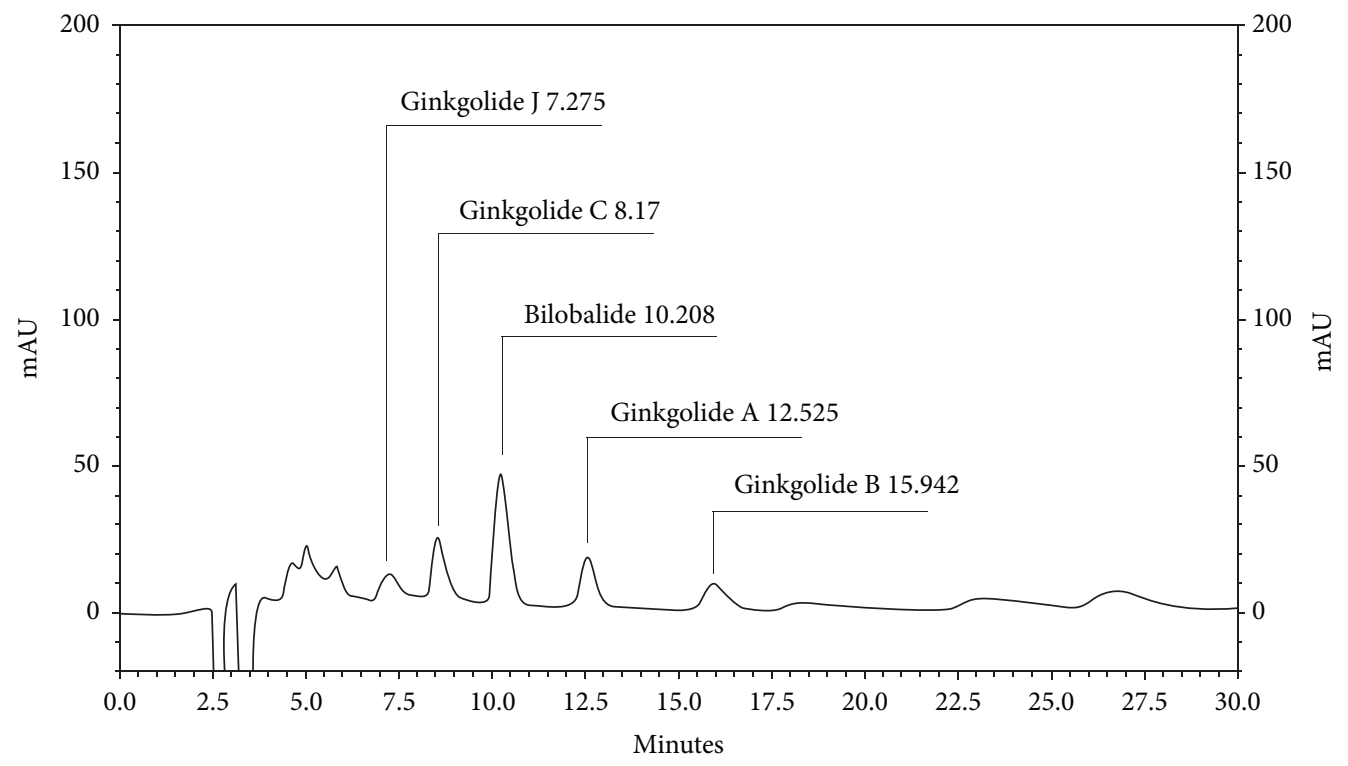

(d)

Figure 1: HPLC characterization of G4E and G24 extracts. Flavonoids and terpenes occurring in G24 and G4E were determined according to EP current edition. (a) Flavonoids in G24 extract; (b) ginkgolides and bilobalide in G24 extract; (c) flavonoids in G4E extract; (d) ginkgolides and bilobalide in G4E extract. G24: acetone extract; G4E: ethanol extract.

(Sigma-Aldrich) for 2 hours, then $\mathrm{TNF} \alpha(20 \mathrm{ng} / \mathrm{mL})$ and ginkgo extracts (G4E and G24) were added to cells for $5 \mathrm{~min}$; medium was removed and cells lysed for $10 \mathrm{~min}$ at RT with $200 \mu \mathrm{L} /$ well of Cell Lysis Mix. Sample lysate was quantified for total protein content by Bradford assay. ELISA was performed in triplicate on $10 \mu \mathrm{g}$ of proteins/well, reading the absorbance at $450 \mathrm{~nm}$ (VictorX3, Perkin Elmer, Waltham MA, USA). Phospho-I $\kappa \mathrm{B} \alpha$ measurement was normalized with the absorbance of the unphosphorylated protein.

2.11. Measurement of Cyclic AMP. HUVECs cultured in 6 -well plates and treated 48 hours late $(60,000 /$ well $)$ were lysed with $0.1 \mathrm{M}$ hydrochloric acid at RT for $20 \mathrm{~min}$. Cells were collected using a scraper and subjected to centrifugation at $1000 \times \mathrm{g}$ for $10 \mathrm{~min}$. The supernatant was transferred into new tubes and total protein content was evaluated by the Bradford method. Samples normalized on the total protein content were diluted $1: 2$ with assay buffer and directly used for evaluation of intracellular cAMP level by cyclic AMP ELISA kit (Cayman Chemical Company, cod. 581001, Ann Arbor, MI, USA) according to the manufacturer's protocol. Absorbance was measured at a wavelength of $405 \mathrm{~nm}$ using an ELISA microplate reader (VictorX3, Perkin Elmer, Waltham MA, USA).

2.12. Statistical Analysis. All data are expressed as mean \pm s.d. of at least three experiments. Data were analyzed by unpaired one-way analysis of variance (ANOVA) followed by Bonferroni test by post hoc test. Statistical analyses were done using GraphPad Prism 6.0 software (GraphPad Software Inc., San Diego, CA, USA). $p<0.05$ was considered statistically significant. $\mathrm{IC}_{50} \mathrm{~s}$ were calculated using the GraphPad Prism 6.0 software.
TABLE 1: Characterization of bilobalide, proanthocyanidins, and flavonoids in ginkgo extracts.

\begin{tabular}{lcc}
\hline & $\begin{array}{c}\text { G24 extract } \\
\%(\text { mean } \pm \text { s.d. })\end{array}$ \\
\hline Bilobalide & $2.94 \pm 0.13$ & $2.87 \pm 0.13$ \\
Proanthocyanidins & $3.62 \pm 2.65$ & $4.81 \pm 2.42$ \\
Flavonol glycosides & $25.31 \pm 1.04$ & $25.03 \pm 0.94$ \\
\hline
\end{tabular}

Results are the mean \pm s.d. of 20 different batches of G24 (acetone) or G4E (ethanol) extracts.

\section{Results and Discussion}

3.1. Characterization of Ginkgo biloba Extracts. Figure 1 reports HPLC profiles of G4E and G24. The extracts showed comparable profiles in flavonoid analysis, showing peaks corresponding to quercetin, kaempferol, and isorhamnetin. Similarly, terpene analysis identified peaks corresponding to ginkgolides (A, B, J, and C) and bilobalide in both the extracts.

Table 1 reports characterization of both G4E and G24 extracts. 20 different batches of each extract were analyzed for total content of flavonol glycosides, proanthocyanidins, and bilobalide. The extracts showed the same profile in terms of proanthocyanidins, bilobalide, and flavonoid content. According to these results, the major classes of constituents occurring in Ginkgo biloba acetone extract, which is considered the most suitable to provide biological activity, are also present in the ethanol G4E extract at comparable concentrations. Standardization was applied as follows: $24 \%$ flavone glycosides and 6.0\% terpene lactones for both G24 and G4E. 


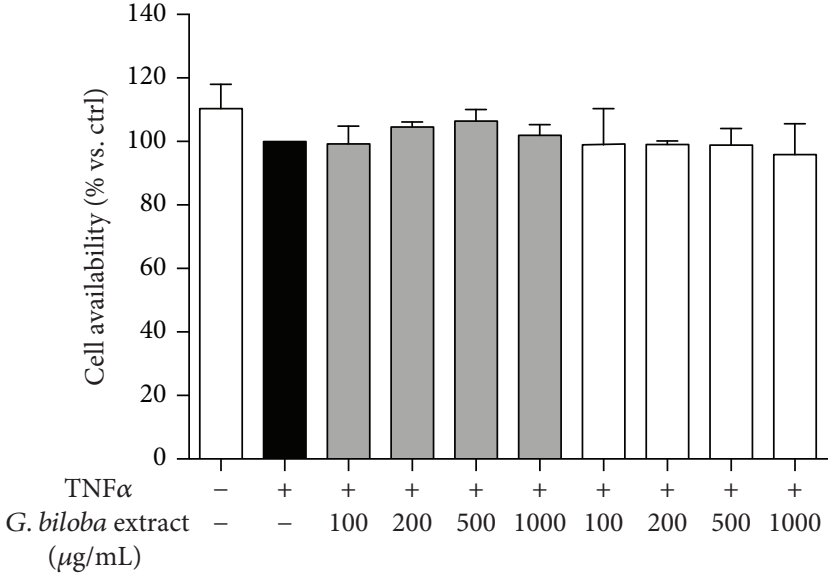

(a)

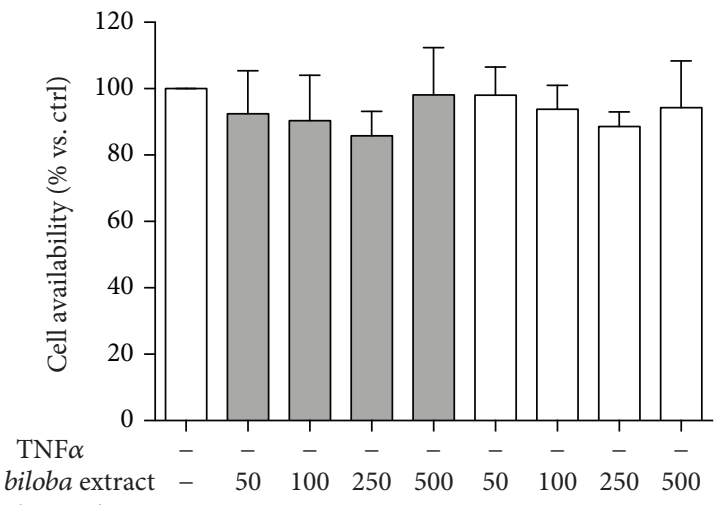

(b)

FIgURE 2: Ginkgo extracts did not impair HUVEC viability in the experimental conditions. Cytotoxicity was neither exhibited during treatment with extracts and TNF $\alpha$ for $6 \mathrm{~h}$ (a) or treatment with extracts for $24 \mathrm{~h}(\mathrm{~b})$.

Thus, we performed a panel of experiments to investigate if similar profiles parallel comparable anti-inflammatory and antioxidant activity in human endothelial cells. No cytotoxicity at concentrations used in the present study was observed in endothelial cells (Figure 2).

\subsection{Ginkgo Extracts Inhibit Cell Surface and Adhesion} Molecule Release in Human Endothelial Cells. In the first set of experiments, the ability of the extracts to impair soluble and cell surface VCAM-1, ICAM-1, and E-selectin in human endothelial cells was investigated. Results are shown in Figure 3. Both the extracts inhibited in a concentrationdependent way adhesion molecule release induced by TNF $\alpha$; however, the extracts slightly inhibited membrane ICAM-1 starting from $250 \mu \mathrm{g} / \mathrm{mL}$ (Figure 3, Table 2). Both the extracts showed higher activity in inhibiting soluble than the membrane forms. Ginkgo extracts showed higher activity on soluble VCAM-1 (41.1 and $43.9 \mu \mathrm{g} / \mathrm{mL}$ for G4E and G24 extracts, respectively) whereas the inhibitory effect on ICAM-1 and E-selectin was less pronounced (Table 2 and Figure 3). Our findings agree with previous investigations by Chen et al., who demonstrated inhibition of adhesion molecules by a Ginkgo biloba standardized extract provided by Dr. Schwabe [5], which is considered comparable to G24 extract.

3.3. Ginkgo Extracts Inhibit NF- $\kappa B$ Pathway in Human Endothelial Cells. Proinflammatory cytokines, such as TNF $\alpha$, activate NF- $\kappa \mathrm{B}$ pathway leading to expression of a variety of proinflammatory mediators, including adhesion molecules. Thus, NF- $\kappa \mathrm{B}$ activation represents a key regulator of adhesion molecule expression in human endothelial cells. NF- $\kappa \mathrm{B}$ is also known as a redox-sensitive transcription factor activated by ROS [29], thus showing proinflammatory and prooxidant properties. NF- $\kappa \mathrm{B}$ activation mainly occurs via $\mathrm{I} \kappa \mathrm{B}$ kinase- (IKK-) mediated phosphorylation of $\mathrm{I} \kappa \mathrm{B} \alpha[30]$. Thus, inhibitors of $I \kappa B \alpha$ phosphorylation may impair the $N F-\kappa B$ pathway leading to an anti-inflammatory effect.
To evaluate if the extracts could impair NF- $\kappa \mathrm{B}$ activation, HUVECs were treated with G4E and G24 for 1 hour; then, nuclear translocation from the cytoplasm into the nucleus was measured by ELISA, as previously described in Materials and Methods. Both the extracts inhibited NF- $\kappa$ B translocation in a concentration-dependent fashion (Figure 4(a)), with comparable $\mathrm{IC}_{50}(75.8$ and $79.9 \mu \mathrm{g} / \mathrm{mL}$ for G4E and G24, respectively). Moreover, the extracts showed a statistically significant decrease of $\mathrm{I} \kappa \mathrm{B} \alpha$ phosphorylation at $250 \mu \mathrm{g} / \mathrm{mL}$, leading to a reduced proteasomal degradation of the NF- $\kappa \mathrm{B}$ inhibitor (Figure 4(b)). Interestingly, we observed a significant effect on cell surface expression of adhesion molecules starting from the same concentration $(250 \mu \mathrm{g} / \mathrm{mL})$ thus remarking NF- $\kappa \mathrm{B}$ impairment as the main mode of action of the extracts. Both inhibition of the NF- $\kappa \mathrm{B}$ nuclear translocation and $\mathrm{I} \kappa \mathrm{B} \alpha$ phosphorylation was confirmed by western blot assays (data not shown).

Previous papers reported the effect of Ginkgo biloba extracts as inhibitors of the NF- $\kappa \mathrm{B}$ activation in a variety of cell lines including endothelial cells [5, 31-33]. Some important beneficial effects of EGb761 extract, which is comparable to G24 for extraction procedure and standardization, are due to the NF- $\kappa \mathrm{B}$ impairment [31]. Our results clearly show that both G4E and G24 extracts similarly inhibit NF- $\kappa$ B translocation at low concentrations, with the same $\mathrm{IC}_{50}$.

3.4. Ginkgo Extracts Inhibit ROS Production in Human Endothelial Cells. During inflammation, immune cells release high amount of ROS which induce oxidative stress in endothelial cells. It is widely known that moderate amounts of ROS have beneficial effects in human health contributing to fight invasion of pathogens or promoting tissue repair processes. Moreover, uncontrolled generation of ROS leads to reduced levels of endogenous antioxidant enzymes (superoxide dismutase, glutathione peroxidase, and catalase), causing oxidative tissue damage.

To investigate if the extracts may counteract oxidative stress showing antioxidant properties, HUVECs were treated with G4E and G24 for 24 hours; thus, cells were incubated 


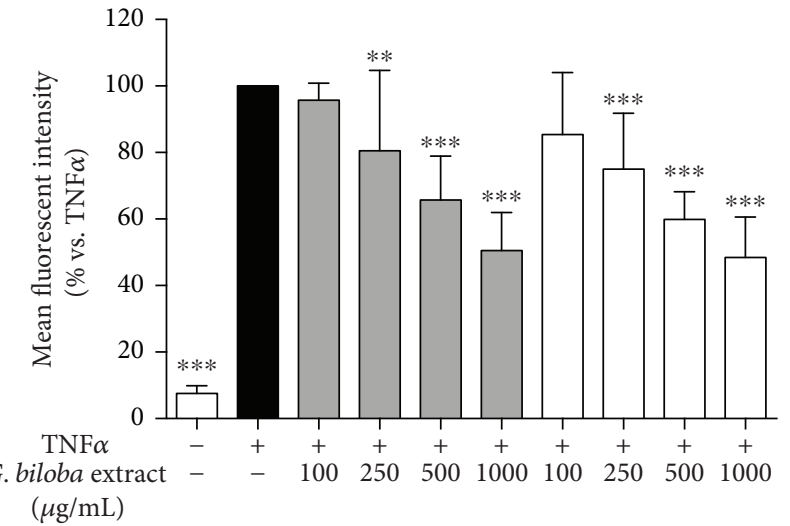

(a)

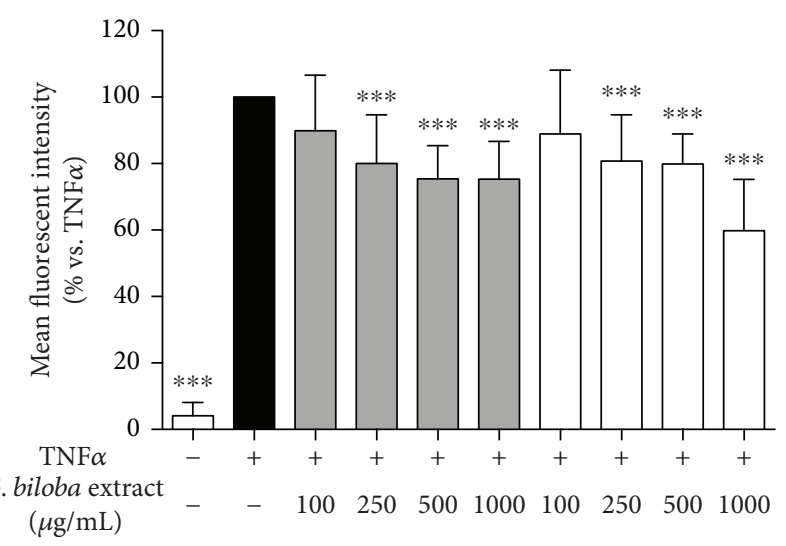

(c)

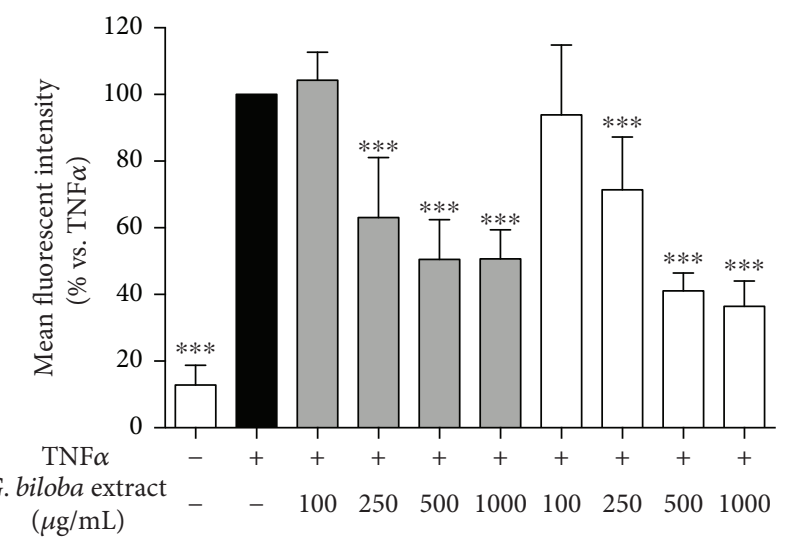

(e)

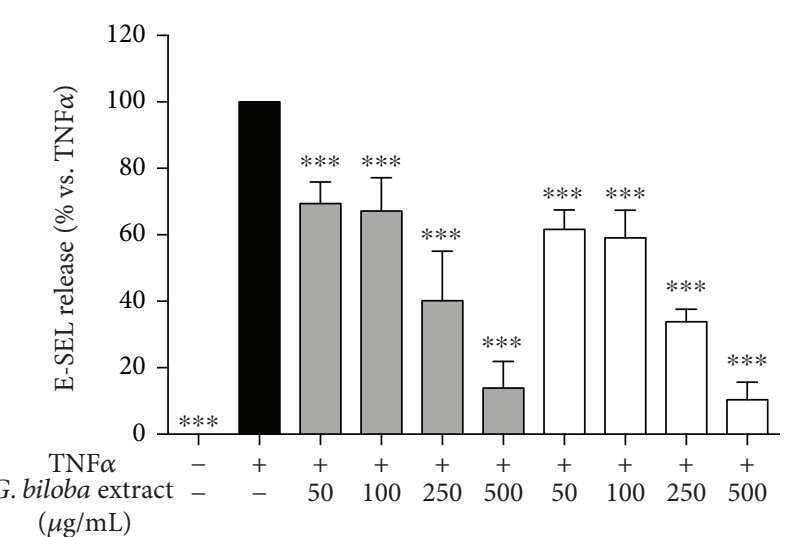

(b)

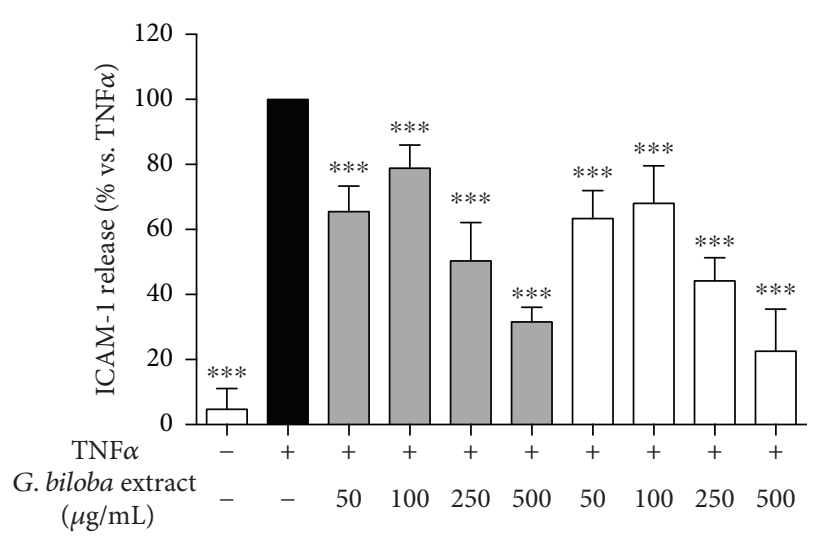

(d)

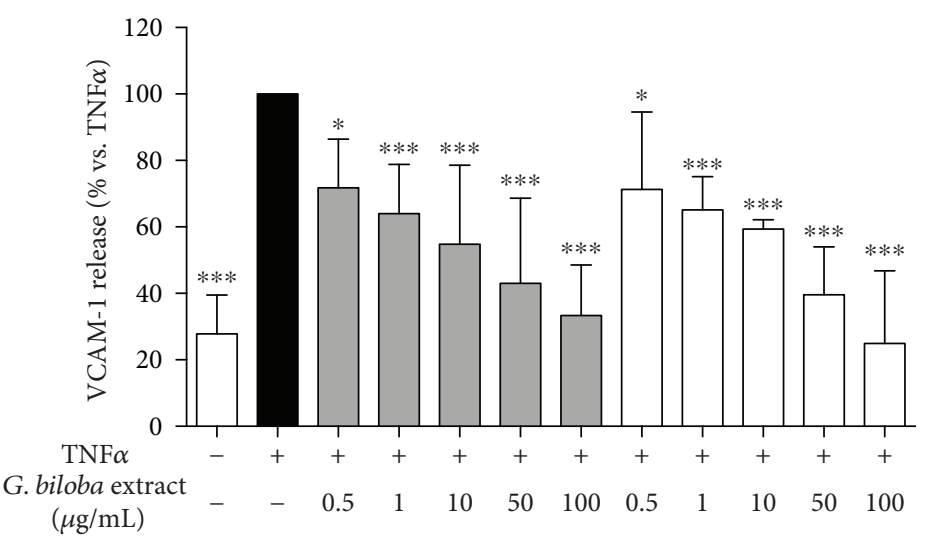

(f)

FIGURE 3: Ginkgo extracts inhibit soluble and cell surface adhesion molecules in human endothelial cells. G4E (grey bars) and G24 (white bars) similarly inhibited E-selectin (a) and VCAM-1 (e) cell surface expression in human endothelial cells; a slight statistically significant inhibition (20-30\%) was observed on ICAM-1 (c) at concentrations starting from $250 \mu \mathrm{g} / \mathrm{mL}$. The inhibition of the extracts on E-selectin (b), ICAM-1 (d), and VCAM-1 (f) release was more pronounced. Curcumin $10 \mu \mathrm{M}$ was used as reference inhibitor of adhesion molecules in all the experiments (average inhibition of $77 \%$ for E-selectin, $96 \%$ for ICAM-1, and 72\% for VCAM-1).

with a fluorescent probe for one hour. Finally, a typical prooxidant stimulus $\left(\mathrm{H}_{2} \mathrm{O}_{2}, 500 \mu \mathrm{M}\right)$ was added for 1 hour to increase ROS production in HUVEC.

Both the extracts inhibited ROS production, although the effect was significant only at the highest concentration tested (Figure 5). Our data agree with previous papers reporting reduction of ROS production and oxidative stress although in different Ginkgo biloba extracts and cell models [5, 34, 35]. However, this is the first report demonstrating that the inhibitory effect on ROS formation in human endothelial cells by G4E and G24 is comparable.

3.5. Effect of Ginkgo Extracts on Adhesion Molecule Gene Expression in Human Endothelial Cells. Since G4E and G24 
TABLE 2: $\mathrm{IC}_{50}$ of ginkgo extracts on adhesion molecules and NF- $\kappa \mathrm{B}$ translocation.

\begin{tabular}{lccccccc}
\hline Form & $\begin{array}{c}\text { Membrane } \\
\text { VCAM-1 }\end{array}$ & $\begin{array}{c}\text { Soluble } \\
\text { sVCAM-1 }\end{array}$ & $\begin{array}{c}\text { Membrane } \\
\text { ICAM-1 }\end{array}$ & $\begin{array}{c}\text { Soluble } \\
\text { sICAM-1 }\end{array}$ & $\begin{array}{c}\text { Membrane } \\
\text { E-sel. }\end{array}$ & $\begin{array}{c}\text { Soluble } \\
\text { sE-sel. }\end{array}$ & $\begin{array}{c}\text { Nuclear } \\
\text { NF- } \kappa \text { B translocation }\end{array}$ \\
\hline G4E & $476.1 \pm 103.7$ & $1.5 \pm 2.4$ & $>1000$ & $226.7 \pm 27.4$ & $849.1 \pm 169.0$ & $159.2 \pm 22.7$ & $75.8 \pm 19.9$ \\
G24 & $372.4 \pm 39.1$ & $1.6 \pm 1.6$ & $>1000$ & $152.5 \pm 26.8$ & $726.8 \pm 160.3$ & $115.9 \pm 15.5$ & $79.9 \pm 18.3$ \\
\hline
\end{tabular}

$\mathrm{IC}_{50} \mathrm{~s}(\mu \mathrm{g} / \mathrm{mL})$ were calculated using GraphPad Prism 6.0 software (GraphPad Software Inc., San Diego, CA, USA). Data represent the mean of at least three experiments performed in duplicate or triplicate. G24: acetone extract; G4E: ethanol extract.

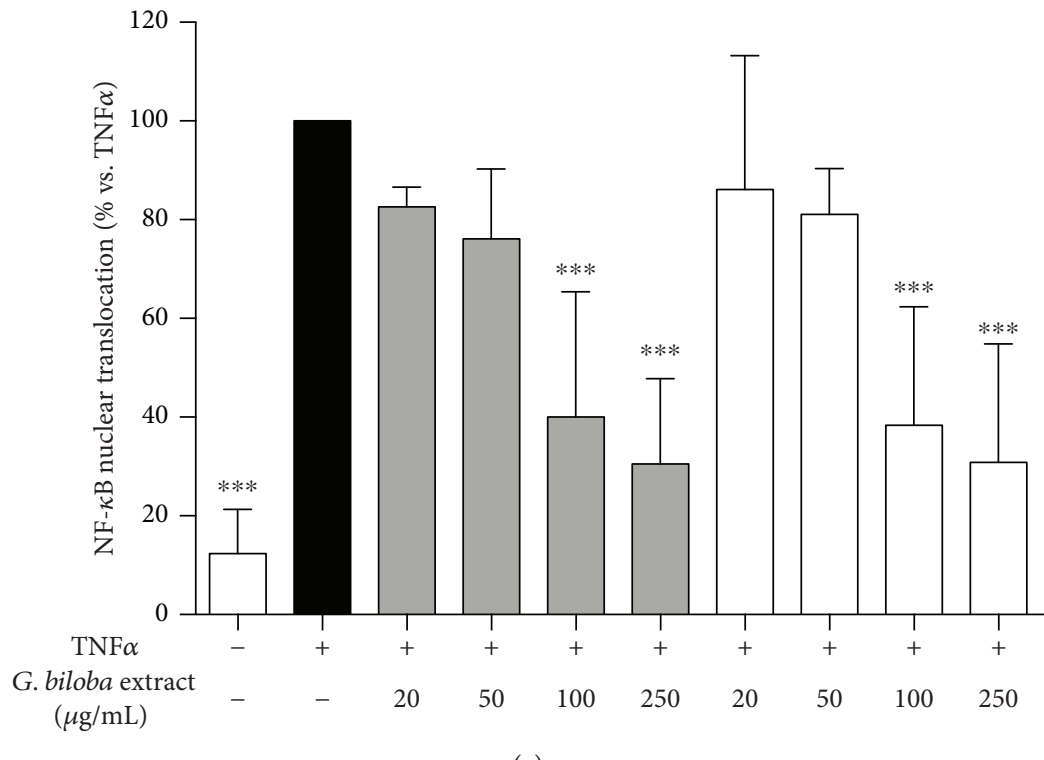

(a)

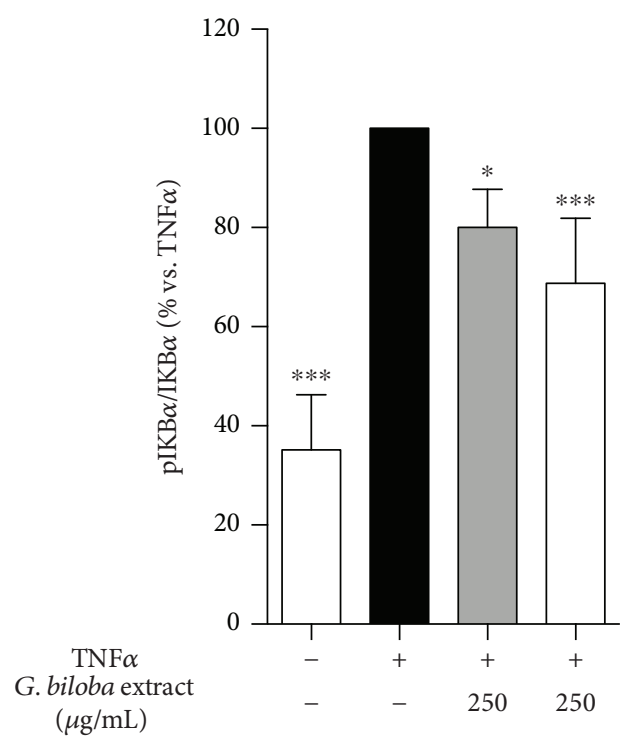

(b)

FIgURE 4: Ginkgo extracts inhibit NF- $\kappa$ B pathway in human endothelial cells. G4E (grey bars) and G24 (white bars) inhibited the NF- $\kappa \mathrm{B}$ nuclear translocation induced by TNF $\alpha$ in a concentration-dependent fashion (a). Epigallocatechin-3-O-gallate (EGCG) $20 \mu \mathrm{M}$ was used as reference compound ( $51 \%$ inhibition). At the highest concentration tested $(250 \mu \mathrm{g} / \mathrm{mL})$, G4E and G24 decrease phosphorylation of the NF- $\kappa \mathrm{B}$ inhibitor $\mathrm{I} \kappa \mathrm{B} \alpha$ (b). G24: acetone extract; G4E: ethanol extract.

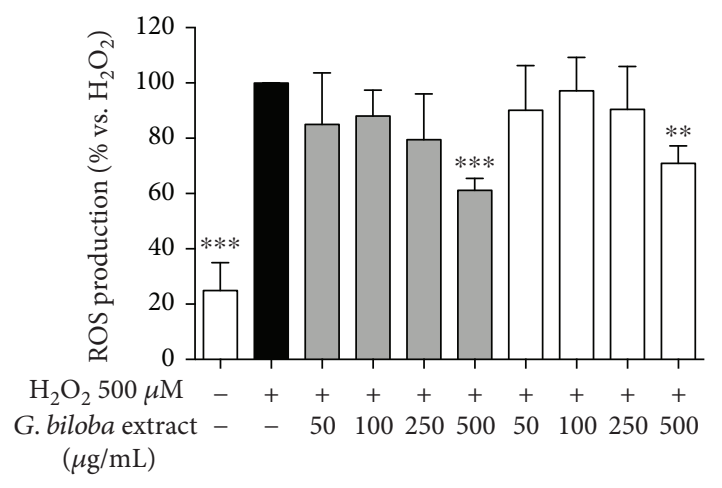

Figure 5: Ginkgo extracts slightly affect ROS production in human endothelial cells. Both the extracts show slight effects on ROS formation, with significant inhibition at the highest concentration $(500 \mu \mathrm{g} / \mathrm{mL})$. G4E (grey bars) and G24 (white bars). Trolox $500 \mu \mathrm{M}$ was used as reference compound (100\% inhibition).

inhibited soluble and cell surface expression of adhesion molecules, we assayed mRNA analysis at the same experimental conditions to verify the effect at transcriptional level. Interestingly, at $250 \mu \mathrm{g} / \mathrm{mL}$, extracts were able to inhibit E- selectin (40-50\%) and slightly ICAM-1 (10-30\%), whereas VCAM-1 transcription was not affected (Figure 6) thus suggesting that E-selectin impairment is regulated by different mechanisms with respect to ICAM-1 and VCAM-1.

Collins et al. [36] collected in detail evidences on how these proteins are regulated at transcriptional level in endothelial cells: $\mathrm{NF}-\kappa \mathrm{B} / \mathrm{I} \kappa \mathrm{B} \alpha$ system plays a crucial role in TNF- $\alpha$-induced expression of adhesion molecules, but a relatively small number of other transcription factors must assemble with NF- $\kappa \mathrm{B}$ to generate unique transcriptionalactivating complexes. Focusing on E-selectin transcription, ATF/CRE (cyclic AMP responsive element) cooperates with $\mathrm{NF}-\kappa \mathrm{B}$, thus E-selectin promoter is susceptible to cAMP regulation. On the other hand, several experiments in HUVECs demonstrated that an increase in cAMP levels caused by cAMP analogues or phosphodiesterase type 3 and 4 inhibitors leads to the inhibition of E-selectin and VCAM-1, but not ICAM-1 membrane expression $[7,10]$. On the contrary, ICAM-1 (both mRNA and surface expression) is upregulated by persistent cAMP elevation during TNF $\alpha$-induced endothelial inflammation, thus suggesting antiphosphodiesterase activity as a possible antagonistic mechanism for extracts displaying NF- $\kappa$ B and ICAM-1 inhibition [37]. 


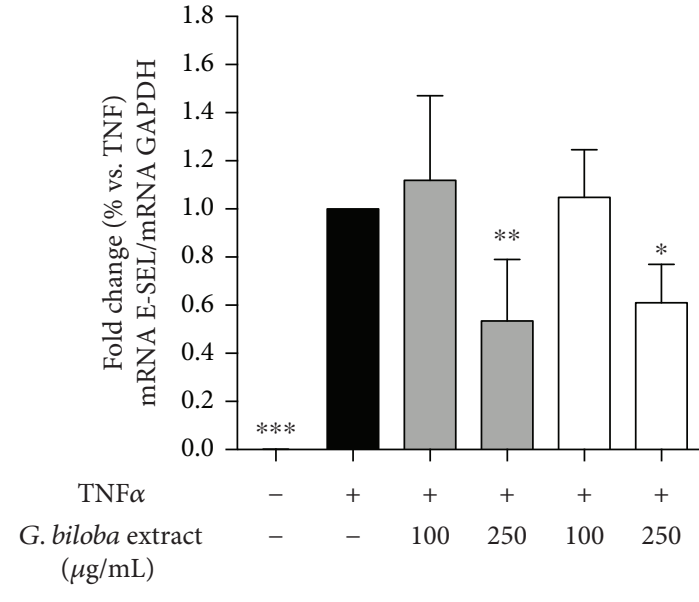

(a)

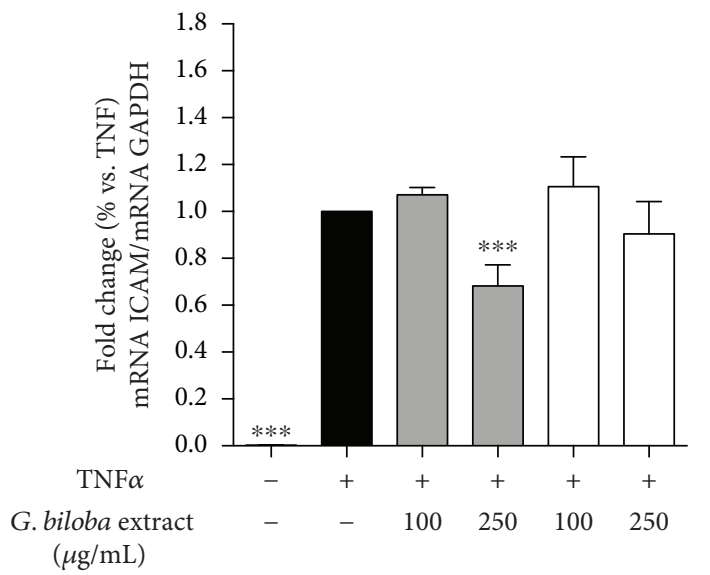

(b)

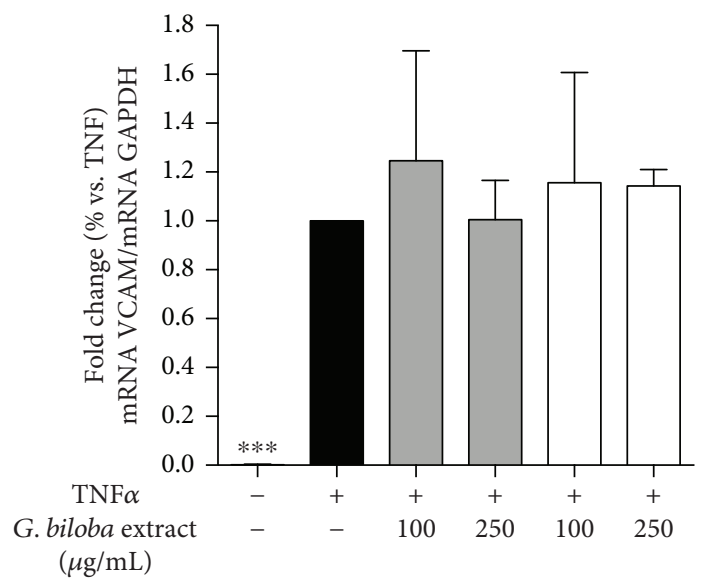

(c)

Figure 6: Effect of ginkgo extracts on adhesion molecules at transcriptional level in human endothelial cells. Ginkgo extracts exhibited a similar inhibitory effect on transcription of adhesion molecules: at $250 \mu \mathrm{g} / \mathrm{mL}$, G4E (grey bars) and G24 (white bars) showed 50\% and $40 \%$ inhibition of E-selectin transcription, respectively (a), while VCAM-1 mRNA was not impaired (c); the slight inhibition of ICAM-1 transcription was significant only for G4E extract (30\% inhibition) (b).

\subsection{Effect of Ginkgo Extracts on Inflammatory Cytokine and} Receptor Gene Expression in Human Endothelial Cells. Since G4E and G24 inhibited the NF- $\kappa$ B pathway in our cell model, we evaluated the overall ability of the extracts to impair a panel of genes involved in endothelial inflammation; data are shown in the supplementary material. TNF $\alpha$ significantly overexpressed 25 genes out of 84, among them 10 were expressed in a statistically significant way; however, both the extracts did not decrease the corresponding mRNA levels, except for the member of the TNF family TNFSF10, which was slightly reduced by acetonic extract G24 (Figure S1).

3.7. Ginkgo Extracts Exhibit cAMP-Elevating Activity. To assess the involvement of cAMP in the anti-inflammatory effect observed in HUVECs, the extracts were tested for their ability to increase cAMP levels in comparison with the wellknown phosphodiesterase inhibitor theophylline $500 \mu \mathrm{M}$ at 1 and 6 hours.

Both G4E and G24 $(250 \mu \mathrm{g} / \mathrm{mL})$ increased cAMP levels after 1 and 6 hours (Figure 7) although the effect was

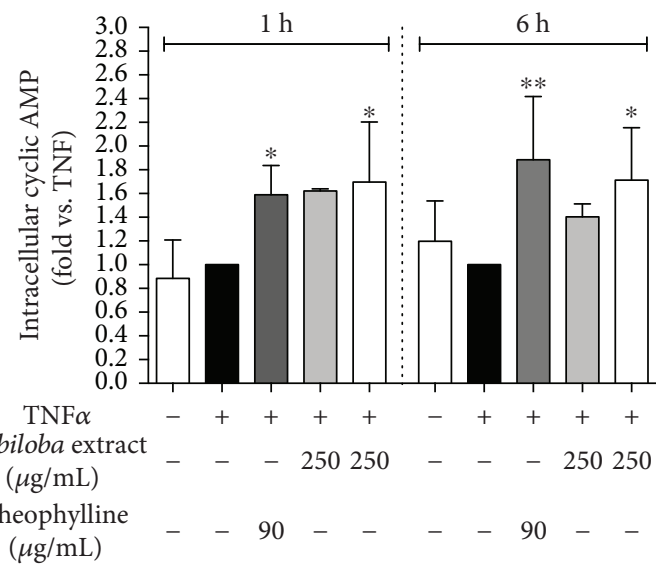

FIgURE 7: Ginkgo extracts increase intracellular cAMP level in human endothelial cells. G4E (grey bars) and G24 (white bars) $250 \mu \mathrm{g} / \mathrm{mL}$ increased intracellular cyclic AMP in HUVECs after 1 and $6 \mathrm{~h}$ treatments. The effect was comparable to the well-known phosphodiesterase inhibitor theophylline $500 \mu \mathrm{M}(90 \mu \mathrm{g} / \mathrm{mL})$, which increased intracellular cyclic AMP of 1.59- and 1.89-folds, respectively, after $1 \mathrm{~h}$ and $6 \mathrm{~h}$, compared to TNF $\alpha$. 


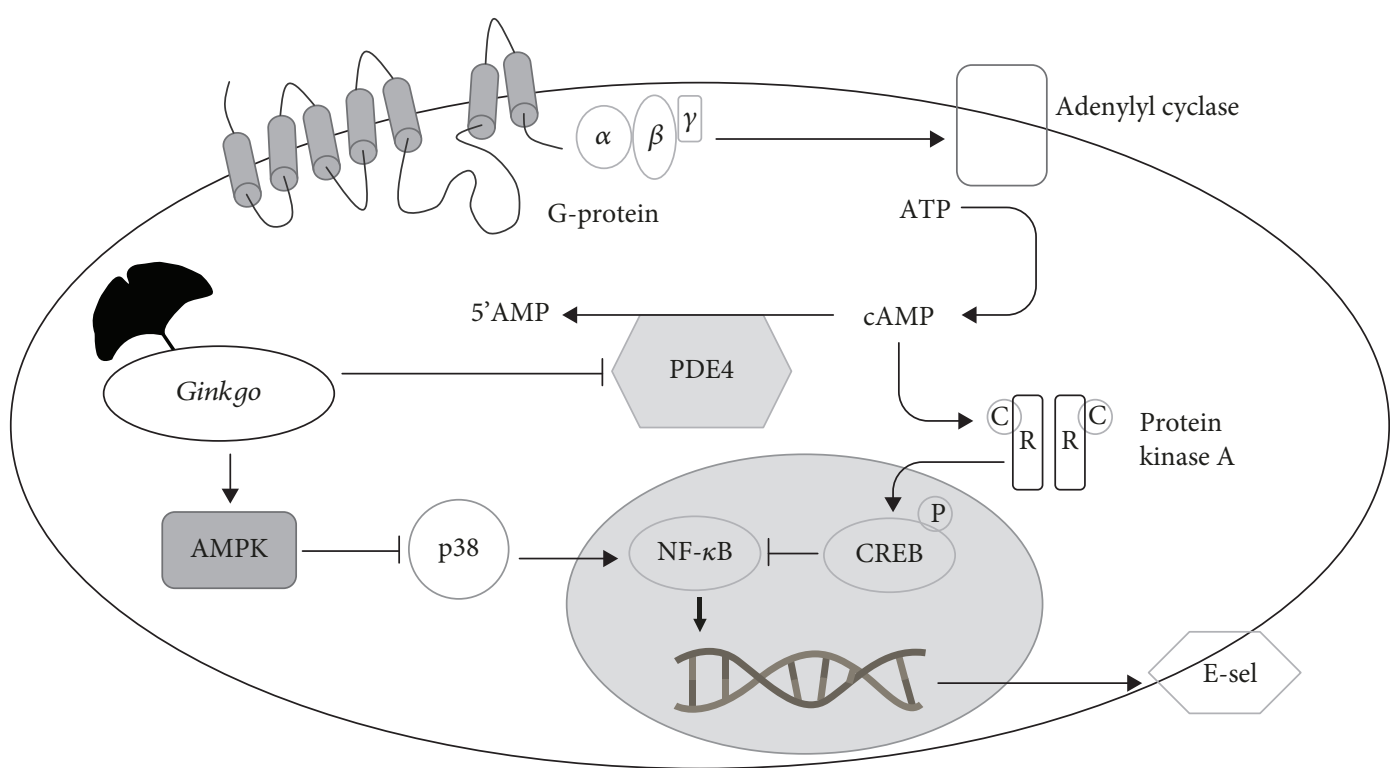

FIGURE 8: Proposed mechanism to explain the effect of ginkgo extracts on signaling cascade involved in E-selectin regulation. Ginkgo could reduce the NF- $\kappa \mathrm{B}$ activation by increasing intracellular cAMP levels acting on PDE4 or by enhancing AMPK activity. Lines with arrows indicate activation, while lines with bars indicate inhibition.

statistically significant only for G24. Our results seem to corroborate the hypothesis that cAMP may negatively regulate E-selectin transcription/surface expression and VCAM-1 surface expression acting on the NF- $\kappa \mathrm{B}$ system. On the contrary, cAMP elevation may have an opposite effect on ICAM1 inhibition. Remarkably, the increase of cAMP following 6 hours of treatment with G24 or G4E paralleled the loss of inhibitory effect on ICAM-1 transcription. Indeed, our findings are partially confirmed by other authors demonstrating that EGB761 extract preferentially inhibits PDE type 4 in HUVECs [38]; in this study performed in primary HUVECs, the extract was effective at lower concentrations thus suggesting that immortalized endothelial cells used in the present study may be less sensitive to the pharmacological effects of the extract. Moreover, it has been previously demonstrated that ginkgolide $\mathrm{C}(10-500 \mu \mathrm{M})$ is able to increase cAMP and CGMP in platelets [39]. Our results, in addition to those occurring in the literature, suggest for the first time that inhibition of E-selectin by Ginkgo biloba extracts in HUVECs may be due, at least in part, to cAMP elevation resulted by PDE inhibition; indeed, it has been previously reported that ginkgo constituents are inhibitors of cGMP- and cAMP-dependent phosphodiesterase [40] [41]. In addition, ginkgo leaf extracts may impair NF- $\kappa \mathrm{B}$ through AMPK activation [32]. It has been demonstrated that other phosphodiesterase inhibitors, such as cilostazol, activate AMPK pathway, which may lead to the impairment of proinflammatory adhesion molecules in platelets and endothelial cells (Figure 8) [42, 43].

Concentrations used in the present research may be considered high and not easily reachable in vivo; however, it has been previously reported that ginkgolides and bilobalide are able to be absorbed in vivo, reaching significant concentrations in blood, according to EMA monograph [21]. Bioavailability of ginkgo flavonoids including kaempferol and quercetin is still controversial. Although variability exists within different formulations, it has been reported that ginkgo flavonoids are absorbed and reach the plasma and brain in detectable amounts in vivo whereas other authors detect only the corresponding glucuronides [44-47]. Taken together, these results allow to hypothesize that in addition to lactones, flavonoids or their metabolites could efficiently show biological activity in endothelial cells [13]. In addition, synergistic effects among ginkgo active compounds cannot be excluded.

\section{Conclusions}

European Pharmacopoeia recommends extraction of Ginkgo powder with acetone; our findings demonstrate for the first time that ethanol (G4E) and acetone (G24) extracts show comparable anti-inflammatory and antioxidant activity in human endothelial cells. In some countries, including Japan, solvents allowed in food supplements or plant extracts are limited to ethanol, thus implying that the usage of standardized ethanol extracts is mandatory. Thus, the results reported herein show that ginkgo extracts made from extraction with acetone or ethanol exhibit similar anti-inflammatory and antioxidant activities, providing new insights into the usage of ethanol extracts in those countries where restrictions in amount of acetone are present. However, different effects of the extracts on other pathways cannot be excluded.

This work clarifies the mode of action by which ginkgo extracts inhibit adhesion molecules acting on different steps of the NF- $\kappa \mathrm{B}$ pathway increasing cAMP levels in human endothelial cells.

Concentrations of the extracts used in the present work may be reached in vivo since lactones, particularly ginkgolides, are adsorbed and reach blood at significant concentrations thus contributing to the biological effects reported herein. 


\section{Data Availability}

The data used to support the findings of the manuscript 6173893 entitled "Comparison of Two Ginkgo biloba L. Extracts on Oxidative Stress and Inflammation Markers in Human Endothelial Cells" are included within the article or in the supplementary information file(s).

\section{Disclosure}

This paper does not necessarily reflect Linnea SA's views of its future policy on this area.

\section{Conflicts of Interest}

Dr. B. Pacchetti is an employee of Linnea SA, Riazzino, CH, a pharmaceutical company that produces and commercializes Ginkgo biloba extracts. The other authors declare that there is no conflict of interest regarding the publication of this article.

\section{Acknowledgments}

Dr. S. Piazza was partially funded by Linnea SA to perform the research reported herein. This research was funded by Linnea SA. This research was supported by grants from MIUR "Progetto Eccellenza."

\section{Supplementary Materials}

The heat map on the left shows 25 genes which are positively regulated by TNF $\alpha$ treatment in HUVECs, while the effect of G4E (grey bars) and G24 (white bars), on the genes which are significantly overexpressed by $\operatorname{TNF} \alpha$, is shown in the respective histograms. The extracts did not significantly impair the expression of the inflammatory genes in HUVECs, with the exception of G24 for TNFSF10 gene. (Supplementary Materials)

\section{References}

[1] M. J. Davies, J. L. Gordon, A. J. H. Gearing et al., "The expression of the adhesion molecules ICAM-1, VCAM-1, PECAM, and E-selectin in human atherosclerosis," The Journal of Pathology, vol. 171, no. 3, pp. 223-229, 1993.

[2] K. D. O'Brien, M. D. Allen, T. O. McDonald et al., "Vascular cell adhesion molecule- 1 is expressed in human coronary atherosclerotic plaques. Implications for the mode of progression of advanced coronary atherosclerosis," The Journal of Clinical Investigation, vol. 92, no. 2, pp. 945-951, 1993.

[3] K. D. O'Brien, T. O. McDonald, A. Chait, M. D. Allen, and C. E. Alpers, "Neovascular expression of E-selectin, intercellular adhesion molecule- 1 , and vascular cell adhesion molecule- 1 in human atherosclerosis and their relation to intimal leukocyte content," Circulation, vol. 93, no. 4, pp. 672-682, 1996.

[4] N. T. Mulvihill, J. B. Foley, P. Crean, and M. Walsh, "Prediction of cardiovascular risk using soluble cell adhesion molecules," European Heart Journal, vol. 23, no. 20, pp. 15691574, 2002.

[5] J. W. Chen, Y. H. Chen, F. Y. Lin, Y. L. Chen, and S. J. Lin, "Ginkgo biloba extract inhibits tumor necrosis factor- $\alpha$ - induced reactive oxygen species generation, transcription factor activation, and cell adhesion molecule expression in human aortic endothelial cells," Arteriosclerosis, Thrombosis, and Vascular Biology, vol. 23, no. 9, pp. 1559-1566, 2003.

[6] J. S. Pober, M. R. Slowik, L. G. De Luca, and A. J. Ritchie, "Elevated cyclic AMP inhibits endothelial cell synthesis and expression of TNF-induced endothelial leukocyte adhesion molecule-1, and vascular cell adhesion molecule-1, but not intercellular adhesion molecule-1," Journal of Immunology, vol. 150, pp. 5114-5123, 1993.

[7] M. J. Sanz, J. Cortijo, M. A. Taha et al., "Roflumilast inhibits leukocyte-endothelial cell interactions, expression of adhesion molecules and microvascular permeability," British Journal of Pharmacology, vol. 152, no. 4, pp. 481-492, 2007.

[8] R. Morandini, G. Ghanem, A. Portier-Lemarie, B. Robaye, A. Renaud, and J. M. Boeynaems, "Action of cAMP on expression and release of adhesion molecules in human endothelial cells," American Journal of Physiology-Heart and Circulatory Physiology, vol. 270, no. 3, pp. H807-H816, 1996.

[9] K. Blease, A. Burke-Gaffney, and P. G. Hellewell, "Modulation of cell adhesion molecule expression and function on human lung microvascular endothelial cells by inhibition of phosphodiesterases 3 and 4," British Journal of Pharmacology, vol. 124, no. 1, pp. 229-237, 1998.

[10] L. G. De Luca, D. R. Johnson, M. Z. Whitley, T. Collins, and J. S. Pober, "cAMP and tumor necrosis factor competitively regulate transcriptional activation through and nuclear factor binding to the cAMP-responsive element/activating transcription factor element of the endothelial leukocyte adhesion molecule-1 (E-selectin) promoter," The Journal of Biological Chemistry, vol. 269, no. 30, pp. 19193-19196, 1994.

[11] T. Soma, T. Kobayashi, A. Yokote, and M. Nagata, "Theophylline attenuates the adhesiveness of endothelial cells augmented with interferon- $\gamma$ in the presence of TNF- $\alpha$ for blood eosinophils," Allergology International, vol. 63, pp. 63-65, 2014.

[12] T. A. van Beek and P. Montoro, "Chemical analysis and quality control of Ginkgo biloba leaves, extracts, and phytopharmaceuticals," Journal of Chromatography A, vol. 1216, no. 11, pp. 2002-2032, 2009.

[13] C. Ude, M. Schubert-Zsilavecz, and M. Wurglics, "Ginkgo biloba extracts: a review of the pharmacokinetics of the active ingredients," Clinical Pharmacokinetics, vol. 52, no. 9, pp. 727-749, 2013.

[14] Y. Z. Wu, S. Q. Li, X. G. Zu, J. du, and F. F. Wang, "Ginkgo biloba extract improves coronary artery circulation in patients with coronary artery disease: contribution of plasma nitric oxide and endothelin-1," Phytotherapy Research, vol. 22, no. 6, pp. 734-739, 2008.

[15] M. Dell'Agli and E. Bosisio, "Biflavones of Ginkgo biloba stimulate lipolysis in 3T3-L1 adipocytes," Planta Medica, vol. 68, no. 1, pp. 76-79, 2002.

[16] M. S. Tan, J. T. Yu, C. C. Tan et al., "Efficacy and adverse effects of Ginkgo biloba for cognitive impairment and dementia: a systematic review and meta-analysis," Journal of Alzheimer's Disease, vol. 43, no. 2, pp. 589-603, 2015.

[17] S. K. Singh, G. E. Barreto, G. Aliev, and V. Echeverria, "Ginkgo biloba as an alternative medicine in the treatment of anxiety in dementia and other psychiatric disorders," Current Drug Metabolism, vol. 18, no. 2, pp. 112-119, 2017.

[18] D. Ong Lai Teik, X. S. Lee, C. J. Lim, C. M. Low, M. Muslima, and L. Aquili, "Ginseng and Ginkgo biloba effects on cognition 
as modulated by cardiovascular reactivity: a randomised trial," PLoS One, vol. 11, no. 3, article e0150447, 2016.

[19] H. F. Zhang, L. B. Huang, Y. B. Zhong et al., "An overview of systematic reviews of Ginkgo biloba extracts for mild cognitive impairment and dementia," Frontiers in Aging Neuroscience, vol. 8, p. 276, 2016.

[20] ESCOP, ESCOP Monographs: The Scientific Foundation for Herbal Medicinal Products, Georg Thieme Verlag, 2009.

[21] Committee on Herb al Medicinal Products (HMPC), European Union herbal monograph on Ginkgo biloba L., folium, 2015.

[22] X. G. Liu, S. Q. Wu, P. Li, and H. Yang, "Advancement in the chemical analysis and quality control of flavonoid in Ginkgo biloba," Journal of Pharmaceutical and Biomedical Analysis, vol. 113, pp. 212-225, 2015.

[23] European Pharmacopoeia, European Pharmacopoeia 8.0, Council of Europe, Strasbourg, France, 2014.

[24] F. Clostre, "Ginkgo biloba extract (EGb 761). State of knowledge in the dawn of the year 2000," Annales Pharmaceutiques Françaises, vol. 57, Supplement 1, pp. 1S8-188, 1999.

[25] "EGb 761: Ginkgo biloba extract, Ginkor," Drugs in $R$ \& $D$, vol. 4, no. 3, pp. 188-193, 2003.

[26] JTJFCR Foundation, Standards for Use of Food Additives Standards Applying Specifically to Inpidual Additives, Japan External Trade Organization (JETRO), 2018.

[27] W. Schmid and J. P. Balz, "Cultivation of Ginkgo biloba L. on three continents," in ISHS Acta Horticulturae 676: III WOCMAP Congress on Medicinal and Aromatic Plants - Volume 2: Conservation, Cultivation and Sustainable Use of Medicinal and Aromatic Plants, pp. 177-180, International Society for Horticultural Science, 2005.

[28] E. Sangiovanni, C. di Lorenzo, E. Colombo et al., "The effect of in vitro gastrointestinal digestion on the anti-inflammatory activity of Vitis vinifera L. leaves," Food \& Function, vol. 6, no. 8, pp. 2453-2463, 2015.

[29] S. Nakajima and M. Kitamura, "Bidirectional regulation of NF- $\kappa$ B by reactive oxygen species: a role of unfolded protein response," Free Radical Biology \& Medicine, vol. 65, pp. 162174, 2013.

[30] P. Viatour, M. P. Merville, V. Bours, and A. Chariot, "Phosphorylation of NF- $\kappa \mathrm{B}$ and $\mathrm{I} \kappa \mathrm{B}$ proteins: implications in cancer and inflammation," Trends in Biochemical Sciences, vol. 30, no. 1, pp. 43-52, 2005.

[31] C. H. Huang, M. L. Yang, C. H. Tsai, Y. C. Li, Y. J. Lin, and Y. H. Kuan, "Ginkgo biloba leaves extract (EGb 761) attenuates lipopolysaccharide-induced acute lung injury via inhibition of oxidative stress and NF- $\kappa \mathrm{B}$-dependent matrix metalloproteinase-9 pathway," Phytomedicine, vol. 20, no. 34, pp. 303-309, 2013.

[32] H. C. Ou, Y. L. Hsieh, N. C. Yang et al., "Ginkgo biloba extract attenuates oxLDL-induced endothelial dysfunction via an AMPK-dependent mechanism," Journal of Applied Physiology, vol. 114, no. 2, pp. 274-285, 2013.

[33] Z. Wei, Q. Peng, B. H. S. Lau, and V. Shah, "Ginkgo biloba inhibits hydrogen peroxide-induced activation of nuclear factor kappa B in vascular endothelial cells," General Pharmacology: The Vascular System, vol. 33, no. 5, pp. 369375, 1999.

[34] D. C. Ren, G. H. Du, and J. T. Zhang, "Protective effect of Ginkgo biloba extract on endothelial cell against damage induced by oxidative stress," Journal of Cardiovascular Pharmacology, vol. 40, no. 6, pp. 809-814, 2002.
[35] X. Zhu, Z. Li, C. Li, J. Zhang, Z. Zou, and J. Wang, "Ginkgo biloba extract and aspirin synergistically attenuate activated platelet-induced ROS production and LOX-1 expression in human coronary artery endothelial cells," Phytomedicine, vol. 20, no. 2, pp. 114-119, 2013.

[36] T. Collins, M. A. Read, A. S. Neish, M. Z. Whitley, D. Thanos, and T. Maniatis, "Transcriptional regulation of endothelial cell adhesion molecules: NF-kappa B and cytokine-inducible enhancers," The FASEB Journal, vol. 9, no. 10, pp. 899-909, 1995.

[37] D. Bernot, F. Peiretti, M. Canault, I. Juhan-Vague, and G. Nalbone, "Upregulation of TNF- $\alpha$-induced ICAM-1 surface expression by adenylate cyclase-dependent pathway in human endothelial cells," Journal of Cellular Physiology, vol. 202, no. 2, pp. 434-441, 2005.

[38] M. Campos-Toimil, C. Lugnier, M.-T. Droy-Lefaix, and K. Takeda, "Inhibition of type 4 phosphodiesterase by rolipram and Ginkgo biloba extract (EGb 761) decreases agonistinduced rises in internal calcium in human endothelial cells," Arteriosclerosis, Thrombosis, and Vascular Biology, vol. 20, no. 9, pp. E34-E40, 2000.

[39] H. J. Cho, Y. H. Shon, and K. S. Nam, "Ginkgolide C inhibits platelet aggregation in cAMP- and cGMP-dependent manner by activating MMP-9," Biological \& Pharmaceutical Bulletin, vol. 30, no. 12, pp. 2340-2344, 2007.

[40] M. Dell'Agli, G. V. Galli, and E. Bosisio, "Inhibition of cGMPphosphodiesterase-5 by biflavones of Ginkgo biloba," Planta Medica, vol. 72, no. 5, pp. 468-470, 2006.

[41] R. Saponara and E. Bosisio, "Inhibition of cAMPphosphodiesterase by biflavones of Ginkgo biloba in rat adipose tissue," Journal of Natural Products, vol. 61, no. 11, pp. 1386-1387, 1998.

[42] N. A. V. da Motta and F. C. F. de Brito, "Cilostazol exerts antiplatelet and anti-inflammatory effects through AMPK activation and NF-kB inhibition on hypercholesterolemic rats," Fundamental \& Clinical Pharmacology, vol. 30, no. 4, pp. 327-337, 2016.

[43] H. J. Hwang, H. S. Chung, T. W. Jung et al., "The dipeptidyl peptidase-IV inhibitor inhibits the expression of vascular adhesion molecules and inflammatory cytokines in HUVECs via Akt- and AMPK-dependent mechanisms," Molecular and Cellular Endocrinology, vol. 405, pp. 25-34, 2015.

[44] J. B. Fourtillan, A. M. Brisson, J. Girault et al., "Pharmacokinetic properties of bilobalide and ginkgolides $\mathrm{A}$ and $\mathrm{B}$ in healthy subjects after intravenous and oral administration of Ginkgo biloba extract (EGb 761)," Thérapie, vol. 50, no. 2, pp. 137-144, 1995.

[45] P. Mauri, A. D. Palma, F. Pozzi et al., "LC-MS characterization of terpene lactones in plasma of experimental animals treated with Ginkgo biloba extracts: Correlation with pharmacological activity," Journal of Pharmaceutical and Biomedical Analysis, vol. 40, no. 3, pp. 763-768, 2006.

[46] K. Woelkart, E. Feizlmayr, P. Dittrich et al., "Pharmacokinetics of bilobalide, ginkgolide A and B after administration of three different Ginkgo biloba L. preparations in humans," Phytotherapy Research, vol. 24, no. 3, pp. 445-450, 2010.

[47] F. Chen, L. Li, F. Xu et al., "Systemic and cerebral exposure to and pharmacokinetics of flavonols and terpene lactones after dosing standardized Ginkgo biloba leaf extracts to rats via different routes of administration," British Journal of Pharmacology, vol. 170, no. 2, pp. 440-457, 2013. 


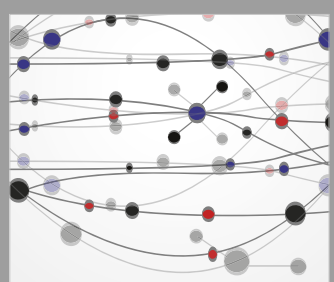

The Scientific World Journal
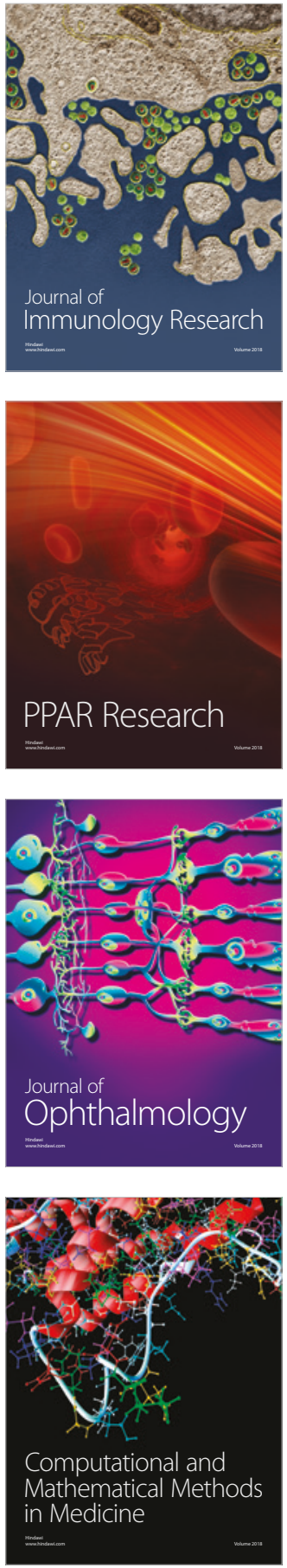

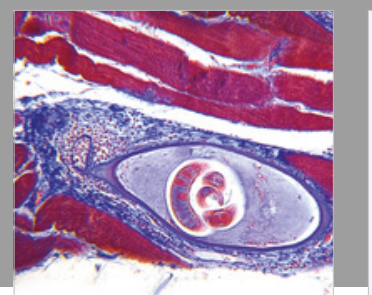

Gastroenterology Research and Practice

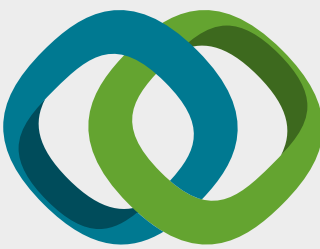

\section{Hindawi}

Submit your manuscripts at

www.hindawi.com
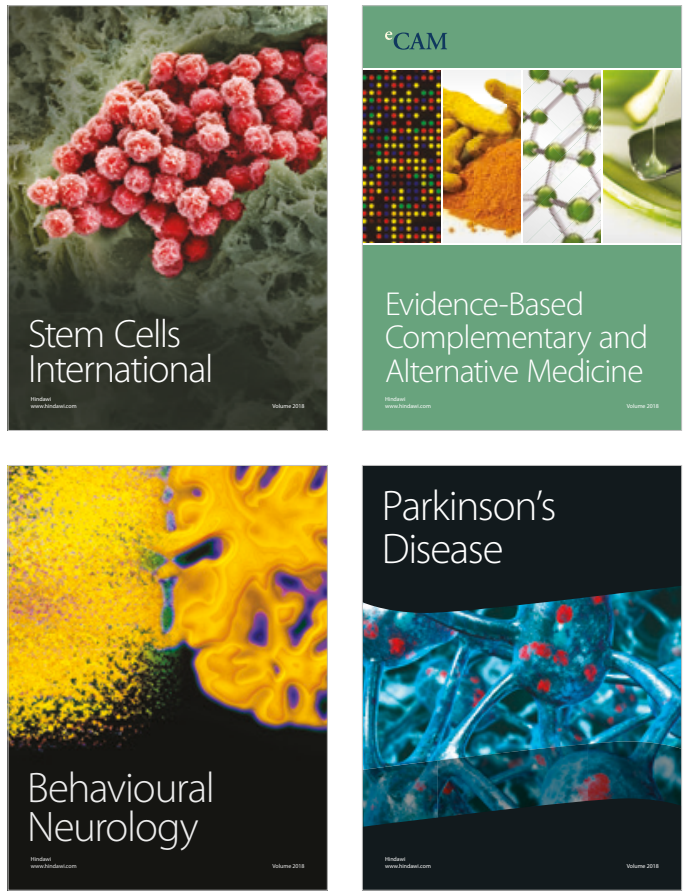

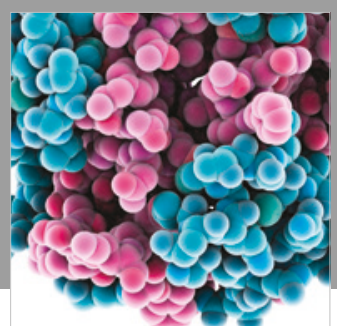

ournal of

Diabetes Research

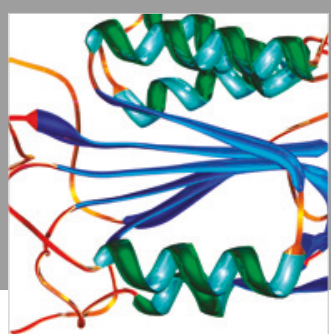

Disease Markers
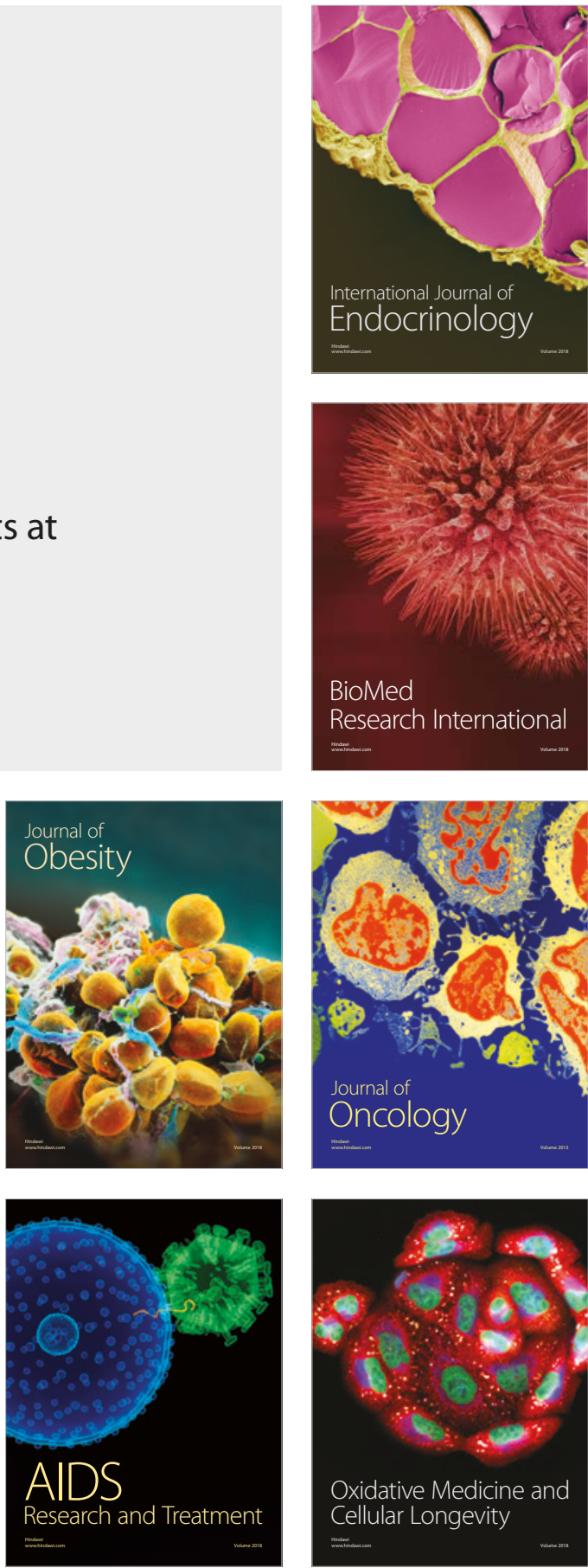